\title{
A synthetic agar assay for determining sensitivity of Venturia inaequalis to anilinopyrimidine fungicides in New Zealand apple orchards
}

\author{
N.J. Larsen ${ }^{1}$, R.M. Beresford ${ }^{1}$, P.N. Wood ${ }^{2}$, P.J. Wright ${ }^{3}$ and B.M. Fisher ${ }^{2}$ \\ ${ }^{1}$ The New Zealand Institute for Plant E Food Research Ltd, Mt Albert Research Centre, \\ Private Bag 92169, Auckland 1142, New Zealand \\ ${ }^{2}$ The New Zealand Institute for Plant \& Food Research Ltd, Hawke's Bay Research Centre, \\ Private Bag 1401, Havelock North, Hastings 4157, New Zealand \\ ${ }^{3}$ The New Zealand Institute for Plant E Food Research Ltd, Pukekohe Research Station, \\ Cronin Road, RD 1, Pukekohe, New Zealand \\ Corresponding author: ngaire.larsen@plantandfood.co.nz
}

\begin{abstract}
A synthetic agar mycelial growth assay, adapted from a Botrytis cinerea method, was used to determine the sensitivity of Venturia inaequalis isolates (the cause of apple black spot) to anilinopyrimidine (AP) fungicides. Nineteen single-conidium isolates were classified as sensitive $(\mathrm{S})$ or resistant $(\mathrm{R})$ to cyprodinil or pyrimethanil after 21 days growth, according to concentrations that inhibited colony diameter by $50 \%\left(\mathrm{EC}_{50}\right)$. Isolate classification on agar was compared with leaf disease control by AP fungicides on potted apple trees inoculated with $\mathrm{S}$ or $\mathrm{R}$ isolates. Three $\mathrm{S}$ isolates were completely inhibited by AP fungicides on plants. Three $\mathrm{R}$ isolates were partially inhibited on fungicide-treated leaves. One isolate, classified as $\mathrm{R}$ for both fungicides on agar, was inhibited by cyprodinil, but not pyrimethanil, on plants. The agar method will be used for screening $V$. inaequalis populations for AP resistance in orchard surveys, with plant tests on some isolates to determine implications for orchard disease control.
\end{abstract}

Keywords fungicide resistance management, mode of action, apple scab, disease management.

\section{INTRODUCTION}

Resistance development in Venturia inaequalis to fungicides with site-specific modes of action threatens to reduce orchard control of apple black spot (scab). This could threaten New Zealand apple exports by reducing growers' ability to meet market standards for disease-free and chemical residue-free fruit. Recent evidence of field resistance in New Zealand has led to investigation of the fungicide groups demethylation inhibitor (DMI) and dodine (Beresford et al. 2012;
Beresford et al. 2013), quinone outside inhibitor (QoI) (Viljanen-Rollinson et al. 2013) and anilinopyrimidine (AP) fungicides, which are the subject of this paper.

The Fungicide Resistance Action Committee (FRAC) considers AP fungicides to be at medium risk from resistance development (Anonymous 1998) and a low frequency of resistance in $V$. inaequalis was reported in Europe in 2011 and 2012 (www.frac.info/). Since their introduction to 
New Zealand in the late 1990s the AP fungicides, pyrimethanil and cyprodinil, have been used under a resistance management strategy that recommends a maximum of five applications per season if mixed with other fungicides, or four applications if not mixed (Beresford et al. 1999).

Methods were needed for testing the sensitivity of $V$. inaequalis isolates to AP fungicides that were compatible with concurrent testing of other fungicide groups. Appropriate test methods depend on fungicide mode of action which, for APs, has been defined for B. cinerea (Lamberth 2012) but not for $V$. inaequalis (Köller et al. 2005). APs are believed to interfere with the biosynthesis of methionine (Masner et al. 1994) and inhibit the secretion of hydrolytic enzymes involved in the pathogen infection process (Milling et al. 1993; Miura et al. 1994). Milling \& Richardson (1995) found that growth of B. cinerea was poorly inhibited by AP fungicides on potato dextrose agar (PDA) because of the presence of sugars that could be used for growth in the presence of the fungicide. Therefore a minimal medium containing sugars whose use by the fungus is blocked by AP fungicide is necessary for in vitro resistance testing. Kunz et al. (1998) considered that methods using host plants were a necessity for testing $V$. inaequalis for AP resistance. However, Henriquez et al. (2011) tested $V$. inaequalis sensitivity on a minimal nutrient agar medium that had been developed by Leroux et al. (1999) for B. cinerea.

This paper reports use of a mycelial growth assay for AP sensitivity using the synthetic agar developed by Leroux et al. (1999). The synthetic agar assay is compared with a plant inoculation assay to determine the reliability of the agar assay in distinguishing resistant from sensitive isolates of $V$. inaequalis. Variability of inhibition over time on agar by AP fungicides for some $V$. inaequalis isolates was also investigated to optimise the mycelial growth assay.

\section{MATERIALS AND METHODS} Isolates of Venturia inaequalis

Nineteen single-conidium isolates of $V$. inaequalis from commercial Waikato, Nelson and Hawke's Bay apple orchards were collected in a national survey over the summer of 201112 (Beresford et al. 2013). To obtain a range of sensitivities to AP fungicides, some of the isolates were selected from integrated fruit production (IFP) orchards, where synthetic fungicides had been used, and some from organic orchards with no synthetic fungicide use. Twelve isolates from IFP orchards that showed the greatest loss in sensitivity to DMI, QoI and dodine fungicides were chosen, together with seven isolates from organic orchards with high sensitivity to these fungicides (Table 1).

\section{Fungicides}

The two AP fungicides tested, cyprodinil and pyrimethanil, were commercial formulations supplied by the manufacturers: Chorus ${ }^{\circledR} 250$ WG (cyprodinil $500 \mathrm{~g} / \mathrm{kg}$ ) and Scala ${ }^{\circledR} 400$ SC (pyrimethanil $400 \mathrm{~g} /$ litre). Each fungicide was diluted in sterile reverse osmosis water for addition to agar media at different concentrations.

\section{Synthetic agar medium}

Mycelial growth of $V$. inaequalis on $\mathrm{Difco}^{\mathrm{TM}}$ PDA was compared with the synthetic medium adapted from Leroux et al. (1999). The synthetic medium contained $10 \mathrm{~g}$ glucose, $1.5 \mathrm{~g} \mathrm{~K}_{2} \mathrm{HPO}_{4}$, $2 \mathrm{~g} \mathrm{KH}_{2} \mathrm{PO}_{4}, 1 \mathrm{~g}\left(\mathrm{NH}_{4}\right)_{2} \mathrm{SO}_{4}, 0.5 \mathrm{~g} \mathrm{MgSO}_{4}$ and $15 \mathrm{~g}$ agar in 1 litre $\mathrm{H}_{2} \mathrm{O}$. Streptomycin sulfate $(100 \mathrm{mg} /$ litre) and ampicillin sodium salt (500 mg/litre) were added to all agar media to inhibit bacteria. Agar was poured into 9-cm vented Petri plates.

\section{Mycelial growth assay}

A 5-mm mycelial plug taken from the growing margin of a 3-month-old $V$. inaequalis colony was inverted and placed on top of the agar. Petri plates were sealed with Parafilm ${ }^{\mathrm{TM}}$ and the isolates were incubated at $20^{\circ} \mathrm{C}$ in natural light. Growth of $V$. inaequalis was measured after 21, 42 and 80 days. The average of two diametric measurements of each colony was recorded each time. Mycelial growth was measured on the synthetic medium amended with cyprodinil or pyrimethanil at $0,0.001,0.01,0.1,1,10$ and $100 \mathrm{mg} /$ litre. The relative growth of each 
isolate was calculated as the average diameter on amended plates as a percentage of that on an unamended control plate. $\mathrm{EC}_{50}$ values (mean fungicide concentration that inhibited mycelial growth by 50\%) were determined from a line graph of relative growth versus $\log _{10}$ fungicide concentration by visually reading the concentration at which the line crossed the 50\% relative growth line. Probit analysis for $\mathrm{EC}_{50}$ determination was not appropriate because of a variable degree of growth stimulation that occurred at low concentrations of the fungicide.

\section{Plant inoculation assay}

The three most sensitive (HB15-20, HB15-3 and HB15-8) and the three most resistant (NE02-11, NE02-17 and NE06-10) V. inaequalis isolates from the mycelial growth assay were tested for their response in terms of disease suppression by AP fungicides on 2-year-old potted 'Royal Gala' apple trees. Plants were treated with a single commercial-rate spray application of three fungicide treatments: (1) cyprodinil (Chorus ${ }^{\circledR}$ applied at $0.3 \mathrm{~g} /$ litre, (2) pyrimethanil (Scala ${ }^{\circledR}$ applied at $0.75 \mathrm{ml} /$ litre) and (3) a water-sprayed control. Two hours after treatment, plants were spray inoculated with $2 \mathrm{ml}$ of $5 \times 10^{4} \mathrm{~V}$. inaequalis conidia/ml, then incubated at $95-98 \%$ relative humidity for $36 \mathrm{~h}$ at $12^{\circ} \mathrm{C}$. Conidial germination of the six $V$. inaequalis isolates averaged $70 \%$ (range 56-80\%). Six replicate shoots were used for each treatment, as two shoots on each of three plants, and the youngest unrolled leaf at the time of inoculation was tagged so that inoculated leaves could be identified later. Plants were laid out in a randomised block design and incubated outdoors for 5 weeks, after which the percentage leaf area covered with sporulating black spot lesions (black spot severity) was assessed on the youngest five inoculated leaves on each shoot. Six trees that were uninoculated and had no fungicide treatment provided a check for background $V$. inaequalis infection in the experimental area. These had a mean black spot severity of $0.1 \%$ at the end of the experiment.

\section{Changes in mycelial growth inhibition on agar over time}

In the mycelial growth assay, some isolates, which at 21 days were inhibited by cyprodinil and pyrimethanil, began to grow later in the 80day observation period. This suggested that over time, there was either degradation of fungicide activity in the agar, or adaptation of the fungus enabling it to grow in the presence of the fungicides. Two isolates were chosen to examine this phenomenon. Isolate HB15-20 (variable sensitivity) was initially sensitive (cyprodinil $\mathrm{EC}_{50}=0.03 \mathrm{mg} /$ litre; pyrimethanil $\mathrm{EC}_{50}=$ $0.37 \mathrm{mg} /$ litre) and began to grow after 80 days on cyprodinil and after 42 days on pyrimethanil. Isolate HB05-13 was consistently sensitive over 80 days, with 21-day $\mathrm{EC}_{50}$ values of $0.03 \mathrm{mg} /$ litre cyprodinil and $0.22 \mathrm{mg} /$ litre pyrimethanil.

The effects of degradation or adaptation were examined in a single experiment using cyprodinil. For degradation, $\mathrm{EC}_{50}$ was determined on 1-day-old and 90-day-old cyprodinil-amended $(0,0.01,0.1$ and $1 \mathrm{mg} /$ litre $)$ plates of the synthetic medium. Adaptation was examined by using mycelial discs taken after 90 days of growth from the margin of colonies grown initially with either no fungicide present (no exposure) or with a sub-lethal concentration of cyprodinil (sub-lethal exposure). Mycelial discs of HB15-20 (variable sensitivity) were taken at 90 days from $0.1 \mathrm{mg} /$ litre cyprodinil plates in the mycelial growth assay. Discs of HB05-13 (consistently sensitive) were taken at 90 days from the 0.01 $\mathrm{mg} /$ litre cyprodinil plates in the mycelial growth assay. Changes in cyprodinil sensitivity of the isolates were compared with initial $\mathrm{EC}_{50}$ values from the mycelial growth assay. Inoculation of plates with $V$. inaequalis, plate incubation and $\mathrm{EC}_{50}$ determination were carried out as in the mycelial growth assay.

\section{Statistical analysis}

Statistical analyses were made using Minitab Release 16 ANOVA to identify significant treatment effects, with mean separation by Fisher's least significant difference (LSD, $\mathrm{P}<0.05$ ). ANOVA of fungicide sensitivity used $\log 10 \mathrm{EC}_{50}$ values, 
rather than $\mathrm{EC}_{50}$ values, to improve normality and variance homogeneity of the data. Mean separation for disease severity data from the plant assay used a generalised linear model with the Tukey Method (95.0\% confidence) on cube-root transformed data, which stabilized the variance.

\section{RESULTS}

\section{Synthetic agar medium}

The growth rate of $V$. inaequalis isolates on the synthetic medium was similar to that on PDA over 80 days. There was a significant regression relationship $(\mathrm{P}<0.001)$ between colony diameter on the synthetic medium (X-axis) and colony diameter on PDA (Y-axis) for all data measurements at 21, 42 and 80 days $(y=0.916 x$ $\left.+3.1, R^{2}=0.82\right)$. Scatter about the regression line was least at 21 days and it increased with increasing incubation time. Although mycelial growth was similar on both types of agar, conidial production occurred on PDA, but was absent on synthetic agar.

\section{Mycelial growth assay}

At 21 days, $\mathrm{EC}_{50}$ values for the least sensitive isolates tested on cyprodinil averaged $3.01 \mathrm{mg} /$ litre, whereas the $\mathrm{EC}_{50}$ values for the most sensitive isolates averaged $0.03 \mathrm{mg} /$ litre (Figure 1). Most of the isolates from conventional IFP orchards had a diminished sensitivity to cyprodinil, while most of those from organic orchards were very sensitive to cyprodinil. The sensitivity of the 19 isolates after 21 days of growth fell into two clear groups, sensitive $\left(\mathrm{EC}_{50}<0.05 \mathrm{mg} /\right.$ litre $)$ and resistant $\left(\mathrm{EC}_{50}>0.5 \mathrm{mg} /\right.$ litre $)$. At 42 days, the data started to vary, with some sensitive isolates showing slightly increased $\mathrm{EC}_{50}$ values. At 80 days, this variation became more pronounced, with six of the nine isolates previously classified as sensitive to cyprodinil growing at $>0.5 \mathrm{mg} /$ litre.

Isolate sensitivity to pyrimethanil was lower than to cyprodinil, although there was the same pattern in sensitivity for individual isolates from IFP and organic orchards. At 21 days, pyrimethanil $\mathrm{EC}_{50}$ values for the least sensitive

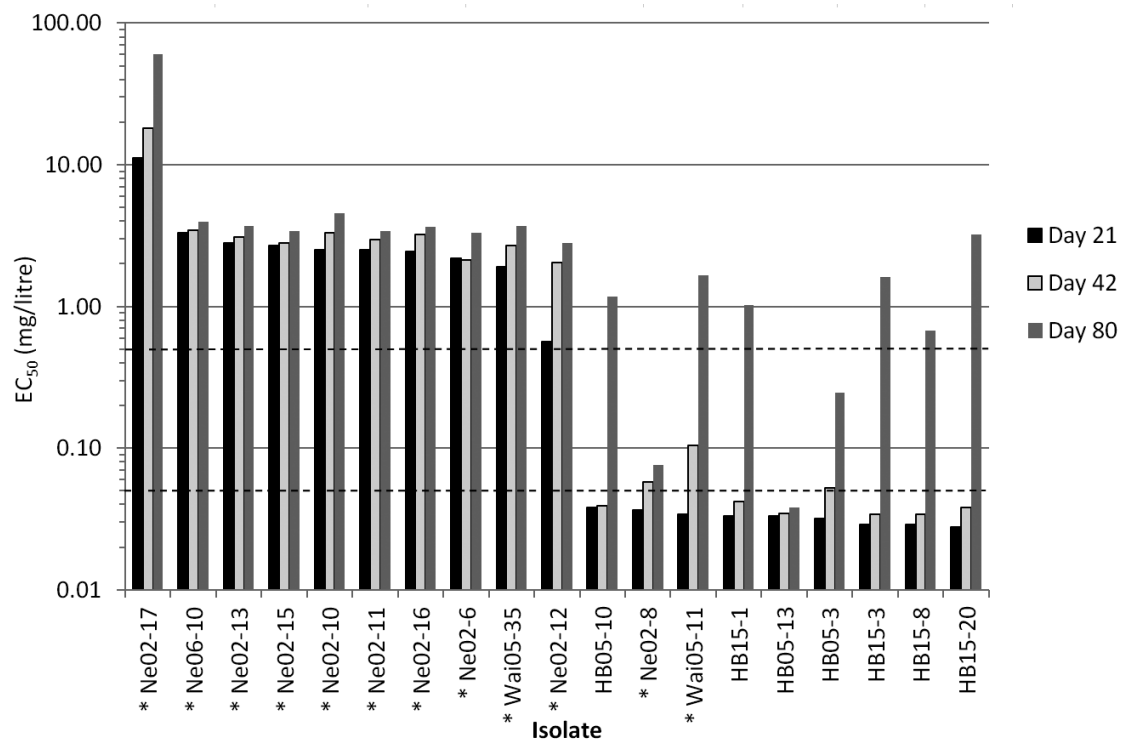

Figure $1 \mathrm{EC}_{50}$ values of 19 Venturia inaequalis isolates tested on synthetic agar containing cyprodinil at 21, 42 and 80 days. Isolates are ranked using day-21 values from least to most sensitive. Asterisks next to the isolate number indicate isolates from integrated fruit production (IFP) apple orchards. Other isolates were from organic orchards. Dashed lines indicate sensitive $(0.05 \mathrm{mg} / \mathrm{litre})$ and resistant $(0.5 \mathrm{mg} /$ litre $)$ thresholds. 
isolates averaged $3.43 \mathrm{mg} /$ litre, while the $\mathrm{EC}_{50}$ values for the most sensitive isolates averaged 0.32 $\mathrm{mg} /$ litre (Figure 2). As with cyprodinil, sensitivity of the 19 isolates after 21 days of growth fell into two groups, with the same nine isolates classified as sensitive $\left(\mathrm{EC}_{50}<0.5 \mathrm{mg} /\right.$ litre) and the same ten isolates classified as resistant $\left(\mathrm{EC}_{50}>2.5 \mathrm{mg} /\right.$ litre $)$. Again, at 42 days, variation in $\mathrm{EC}_{50}$ values began to occur, with one isolate (HB15-20) growing at $>2.5$ $\mathrm{mg} /$ litre $\left(\mathrm{EC}_{50} 4.79 \mathrm{mg} /\right.$ litre $)$. After 80 days, more variation was observed and three more isolates that were classified as sensitive after 21 days would have been classified as resistant after 80 days.

\section{Plant inoculation assay}

Separation of treatment means for black spot severity, which was done on cube roottransformed data, showed two main groups that were significantly different from each other $(\mathrm{P}<0.05)$. The first group (A) had the greatest severity and contained all the no-fungicide treatments, isolate $\mathrm{Ne} 02-17$ growing in the presence of either cyprodinil or pyrimethanil, and isolate Ne06-10 growing in the presence of pyrimethanil (Figure 3). In this group mean black spot severity was $>6 \%$, even when fungicides were applied. The second group (B) had the least severity and contained isolates HB15-20, HB153 and HB15-8 (sensitive on agar) growing in the presence of either cyprodinil or pyrimethanil, as well as isolate $\mathrm{Ne} 06-10$ growing in the presence of cyprodinil. In this group mean severity was below $1.0 \%$. For isolate Ne02-11, mean severity was not significantly different from groups A or $\mathrm{B}$ in the presence of either cyprodinil (5.2\%) or pyrimethanil $(4.3 \%)$.

There was general agreement in sensitivity of isolates between the agar and plant inoculation assays (Table 1). The three selected isolates that showed high sensitivity to AP fungicides on agar were also sensitive in the plant assay. Two of the three isolates that were classified as resistant on agar were also resistant on plants. Isolate NE02-17, which was the least sensitive to both cyprodinil and pyrimethanil on agar (Figures 1 \& 2), was also the least sensitive on leaves in the presence of either fungicide (Figure 3). Isolate Ne06-10 was resistant to both fungicides on agar

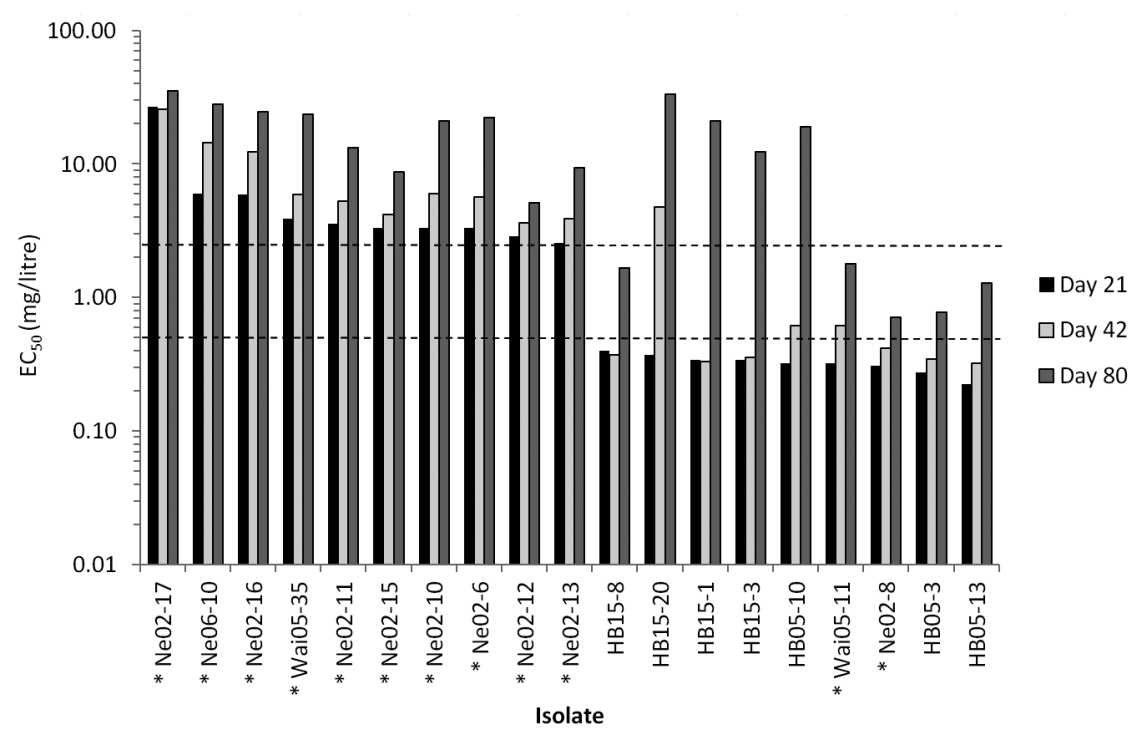

Figure $2 \mathrm{EC}_{50}$ values of 19 Venturia inaequalis isolates tested on synthetic agar containing pyrimethanil at 21, 42 and 80 days. Isolates are ranked using day-21 values from least to most sensitive. Asterisks next to the isolate number indicate isolates from integrated fruit production (IFP) apple orchards. Other isolates were from organic orchards. Dashed lines indicate sensitive $(0.5 \mathrm{mg} / \mathrm{litre})$ and resistant (2.5 mg/litre) thresholds. 
(Figures $1 \& 2$ ), but in the plant assay (Figure 3), it was sensitive to cyprodinil (mean severity= $0.8 \%$ ) but relatively insensitive to pyrimethanil (mean severity $=6.4 \%)$.

\section{Changes in mycelial growth inhibition on agar over time}

To examine changes in sensitivity to cyprodinil of isolates HB15-20 (variable sensitivity) and HB05-13 (consistently sensitive) in relation to agar age and pre-exposure to cyprodinil, $\mathrm{EC}_{50}$ values were compared with thresholds from the mycelial growth assay after 21 days. A sensitive response was $\mathrm{EC}_{50}<0.05 \mathrm{mg} /$ litre and a resistant response was $\mathrm{EC}_{50}>0.5 \mathrm{mg} /$ litre.

Twenty-one days into the experiment the two isolates showed no apparent difference in $\mathrm{EC}_{50}$ value between 1-day-old and 90-day-old agar (Table 2), indicating there had been no degradation of fungicide activity in the agar

Table 1 Venturia inaequalis isolates classified as resistant (R) or sensitive (S) to cyprodinil and pyrimethanil in the agar (19 isolates assessed at 21 days) and plant assays (six isolates assessed at 5 weeks). For each isolate region of origin, apple cultivar and production system are shown. Resistant (R) isolates for the agar tests had cyprodinil $\mathrm{EC}_{50}>0.5 \mathrm{mg} /$ litre and pyrimethanil $\mathrm{EC}_{50}>2.5 \mathrm{mg} /$ litre; $\mathrm{R}$ isolates for the plant tests had $>1 \%$ mean disease severity.

\begin{tabular}{|c|c|c|c|c|c|}
\hline \multirow[b]{2}{*}{ Isolate no. ${ }^{1}$} & \multirow{2}{*}{$\begin{array}{l}\text { Apple cultivar and } \\
\text { production system }^{2}\end{array}$} & \multicolumn{2}{|c|}{ Agar tests } & \multicolumn{2}{|c|}{ Plant tests } \\
\hline & & Cyprodinil & Pyrimethanil & Cyprodinil & Pyrimethanil \\
\hline НВ05-10 & 'Braeburn'/Organic & S & S & - & - \\
\hline НB05-13 & 'Braeburn'/Organic & S & $\mathrm{S}$ & - & - \\
\hline HB05-3 & 'Braeburn'/Organic & $S$ & $S$ & - & - \\
\hline HB15-1 & 'Braeburn'/Organic & S & S & - & - \\
\hline HB15-20 & 'Braeburn'/Organic & S & $\mathrm{S}$ & S & S \\
\hline HB15-3 & 'Braeburn'/Organic & S & $\mathrm{S}$ & S & S \\
\hline HB15-8 & 'Braeburn'/Organic & S & $\mathrm{S}$ & S & S \\
\hline $\mathrm{Ne} 02-10$ & 'Royal Gala'/IFP & $\mathrm{R}$ & $\mathrm{R}$ & - & - \\
\hline $\mathrm{Ne} 02-11$ & 'Royal Gala'/IFP & $\mathrm{R}$ & $\mathrm{R}$ & $\mathrm{R}$ & $\mathrm{R}$ \\
\hline $\mathrm{Ne} 02-12$ & 'Royal Gala'/IFP & $\mathrm{R}$ & $\mathrm{R}$ & - & - \\
\hline $\mathrm{Ne} 02-13$ & 'Royal Gala'/IFP & $\mathrm{R}$ & $\mathrm{R}$ & - & - \\
\hline $\mathrm{Ne} 02-15$ & 'Royal Gala'/IFP & $\mathrm{R}$ & $\mathrm{R}$ & - & - \\
\hline $\mathrm{Ne} 02-16$ & 'Royal Gala'/IFP & $\mathrm{R}$ & $\mathrm{R}$ & - & - \\
\hline $\mathrm{Ne} 02-17$ & 'Royal Gala'/IFP & $\mathrm{R}$ & $\mathrm{R}$ & $\mathrm{R}$ & $\mathrm{R}$ \\
\hline $\mathrm{Ne} 02-6$ & 'Royal Gala'/IFP & $\mathrm{R}$ & $\mathrm{R}$ & - & - \\
\hline $\mathrm{Ne} 02-8$ & 'Royal Gala'/IFP & S & S & - & - \\
\hline $\mathrm{Ne} 06-10$ & 'Royal Gala'/IFP & $\mathrm{R}$ & $\mathrm{R}$ & S & $\mathrm{R}$ \\
\hline Wai05-11 & 'Royal Gala'/IFP & S & $\mathrm{S}$ & - & - \\
\hline Wai05-35 & 'Royal Gala'/IFP & $\mathrm{R}$ & $\mathrm{R}$ & - & - \\
\hline
\end{tabular}

${ }^{1} \mathrm{HB}=$ Hawke's Bay, $\mathrm{Ne}=$ Nelson, Wai $=$ Waikato.

${ }^{2} \mathrm{IFP}=$ Integrated fruit production. 


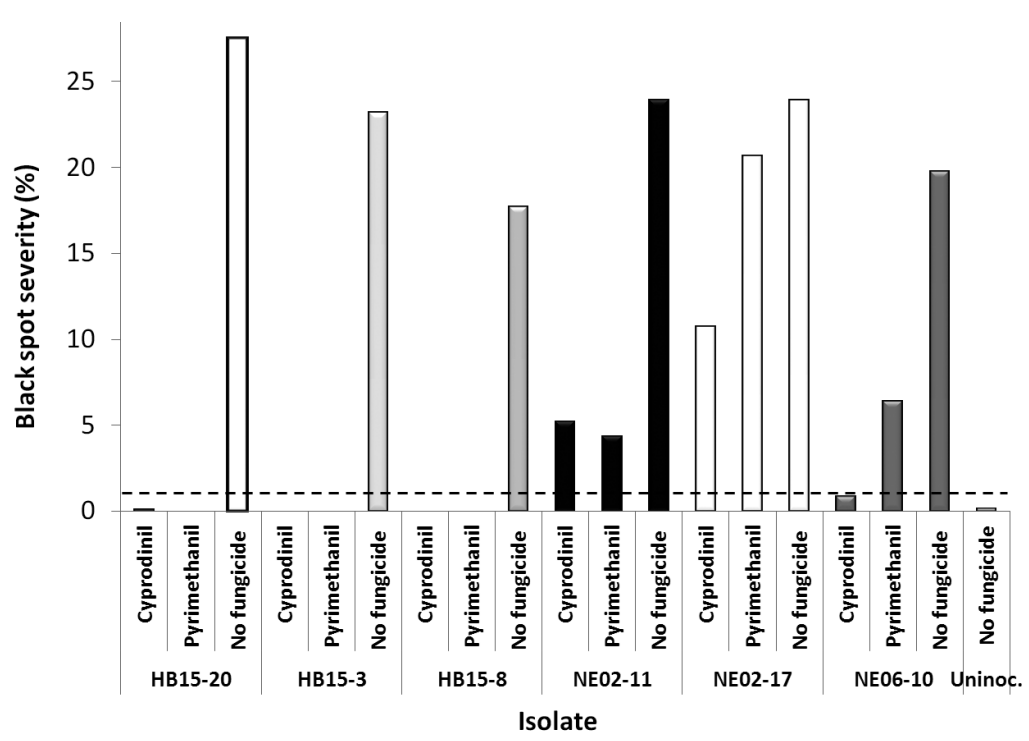

Figure 3 Mean black spot severity (percentage leaf area with sporulating Venturia inaequalis) on leaves of apple plants treated with cyprodinil or pyrimethanil then inoculated with isolates of $V$. inaequalis that were either sensitive (HB15-20, HB15-3 and HB15-8) or resistant (NE02-11, NE02-17 and NE06-10) to these fungicides in the mycelial growth assay. No-fungicide controls were inoculated but not treated with fungicide and the uninoculated control was neither inoculated nor fungicide-treated. The dashed line indicates a threshold of $1 \%$ mean severity, below which isolates were considered fungicide-sensitive.

over 90 days. Similarly there was no apparent $\mathrm{EC}_{50}$ difference as a result of exposure history of the isolates, suggesting no adaptation to the fungicide had occurred during the previous 80 days of exposure to the fungicide.

Forty-two days into the experiment, isolate HB05-13 (consistently sensitive) again showed no effect on $\mathrm{EC}_{50}$ value from either agar age or exposure history (Table 2). However, isolate HB15-20 (variable sensitivity) had an increased $\mathrm{EC}_{50}$ value on both 1-day-old (0.066 mg/litre) and 90 -day-old $(0.191 \mathrm{mg} /$ litre $)$ agar. The $\mathrm{EC}_{50}$ on 1-day-old agar was higher than the value obtained in the mycelial growth assay $(0.038$ $\mathrm{mg} /$ litre), but was only just over the sensitive threshold of $0.05 \mathrm{mg} / \mathrm{litre}$. When HB15-20 had had previous exposure to the fungicide, the $\mathrm{EC}_{50}$ values increased to 0.24 and $0.282 \mathrm{mg} /$ litre on 1 and 90-day-old agar, respectively.

After 80 days, $\mathrm{EC}_{50}$ values for HB05-13 where there had been no previous exposure to cyprodinil were greater ( 0.145 for 1 -day-old agar and 0.105 for 90-day-old agar) than the $\mathrm{EC}_{50}$ value obtained in the mycelial growth assay (0.038). However, this isolate-exposure combination would not be considered resistant, as the $\mathrm{EC}_{50}$ value was not greater than $0.5 \mathrm{mg} /$ litre. Where HB05-13 had had previous exposure to cyprodinil, it remained sensitive on both 1-day-old and 90-day-old agar and had identical $\mathrm{EC}_{50}$ values (0.028). For isolate HB15-20, on both agars, with and without prior exposure to the fungicide, growth was $>50 \%$ of the un-amended control even at the highest cyprodinil concentration (1 $\mathrm{mg} /$ litre) and, therefore, $\mathrm{EC}_{50}$ values could only be estimated as $>1 \mathrm{mg} /$ litre, which was a resistant response $\left(\mathrm{EC}_{50}>0.5 \mathrm{mg} / \mathrm{litre}\right)$.

\section{DISCUSSION}

Although this study investigated only nineteen $V$. inaequalis isolates, it provided convincing evidence that the synthetic agar mycelial growth assay will be a useful tool for screening orchard populations for shifts in sensitivity 
Table 2 Cyprodinil $\mathrm{EC}_{50}$ values (concentration in $\mathrm{mg}$ /litre that inhibited growth by $50 \%$ ) of two Venturia inaequalis isolates with different exposure history and grown on agar of different ages. $\mathrm{EC}_{50}$ values in brackets show each isolate's response in the initial assay on 1-day-old-agar with no previous exposure to cyprodinil. $\mathrm{EC}_{50}$ values in bold are greater than the $0.05 \mathrm{mg} /$ litre $\mathrm{EC}_{50}$ threshold that classified isolates as sensitive and underlined $\mathrm{EC}_{50}$ values are greater than the $0.5 \mathrm{mg} /$ litre $\mathrm{EC}_{50}$ threshold that classified isolates as resistant.

\begin{tabular}{|c|c|c|c|}
\hline Isolate and sensitivity type & Fungicide exposure history & 1-day-old agar & 90-day-old agar \\
\hline \multicolumn{4}{|l|}{21 days } \\
\hline \multirow{2}{*}{ HB15-20 (variable sensitivity) } & No exposure & $0.028(0.028)$ & 0.030 \\
\hline & Sub-lethal exposure & 0.030 & 0.030 \\
\hline \multirow{2}{*}{$\begin{array}{l}\text { HB05-13 (consistently } \\
\text { sensitive) }\end{array}$} & No exposure & $0.023(0.033)$ & 0.028 \\
\hline & Sub-lethal exposure & 0.034 & 0.012 \\
\hline \multicolumn{4}{|l|}{42 days } \\
\hline \multirow{2}{*}{ HB15-20 (variable sensitivity) } & No exposure & $0.066(0.038)$ & 0.191 \\
\hline & Sub-lethal exposure & 0.24 & 0.282 \\
\hline \multirow{2}{*}{$\begin{array}{l}\text { HB05-13 (consistently } \\
\text { sensitive) }\end{array}$} & No exposure & $0.044(0.035)$ & 0.033 \\
\hline & Sub-lethal exposure & 0.036 & 0.028 \\
\hline \multicolumn{4}{|l|}{80 days } \\
\hline \multirow{2}{*}{ HB15-20 (variable sensitivity) } & No exposure & $\geq 1(\underline{3.236})$ & $\geq 1$ \\
\hline & Sub-lethal exposure & $\geq 1$ & $\geq 1$ \\
\hline \multirow{2}{*}{$\begin{array}{l}\text { HB05-13 (consistently } \\
\text { sensitive) }\end{array}$} & No exposure & $0.145(0.038)$ & 0.105 \\
\hline & Sub-lethal exposure & 0.028 & 0.028 \\
\hline
\end{tabular}

to AP fungicides. After 21 days of growth, there was clear differentiation of isolates into two sensitivity groups and both cyprodinil and pyrimethanil gave similar responses. For cyprodinil, sensitive isolates had $\mathrm{EC}_{50}<0.05 \mathrm{mg} /$ litre and resistant isolates had $\mathrm{EC}_{50}>0.5 \mathrm{mg} /$ litre. For pyrimethanil, sensitive isolates had $\mathrm{EC}_{50}<0.5 \mathrm{mg} /$ litre and resistant isolates had $\mathrm{EC}_{50}>2.5 \mathrm{mg} /$ litre. No isolates had intermediate values at 21 days.

Isolates classified as sensitive in vitro were also sensitive when evaluated for disease suppression by AP fungicides on plants, but isolates classified as resistant in vitro showed some variability in disease control by APs on plants. One of three isolates classified as resistant on agar (Ne02-11) was partially controlled by both fungicides on plants. However, this isolate was not fully sensitive and its plant response was clearly different from the response of the isolates classified as sensitive on agar. The implications for orchard disease control of resistance detected by the synthetic agar assay needs to be determined using the plant inoculation assay, for at least a selection of the isolates collected in orchard surveys. The fact that both sensitive and resistant $V$. inaequalis isolates caused similar disease severity on plants not treated with an AP fungicide indicates there was no loss of pathogenic fitness associated with the degree of AP resistance encountered in this study.

The time-related decrease in sensitivity to AP fungicides for some isolates grown on the synthetic agar mycelia growth assay for up to 80 days was similar for both the AP fungicides tested. In the further investigation of changes in growth inhibition over time using cyprodinil the changes were inconsistent between the two fungicide exposure histories. This suggests that resistance was not acquired in these vegetatively growing colonies by adaptation after previous exposure to the fungicide. The sensitivity decrease was also clearly not the result of degradation of the fungicide in the agar. It appeared to be a genetic 
feature of some sensitive isolates and it did not relate to disease control by AP fungicides on plants, as shown by the high degree of inhibition of isolate HB15-20 (variable sensitivity) in the plant assay. These results show that when using the synthetic agar mycelial growth assay to determine AP sensitivity, growth measurements should be taken after no more than 21 days.

Variability in sensitivity of $V$. inaequalis to AP fungicides on agar has been attributed to the inability of APs to inhibit growth on complex nutrient media, like PDA, where growth can occur in the presence of AP fungicides (Köller et al. 2005). However, the synthetic medium modified with different concentrations of AP fungicides used in this study was able to differentiate between sensitive and resistant isolates. The similarity of growth rate of $V$. inaequalis on the synthetic medium and PDA showed that the synthetic agar provided sufficient nutrition for fungal growth for the duration of the mycelial sensitivity tests. In this study the synthetic agar assay detected sensitive isolates reliably, but the degree to which its detection of resistant isolates might overestimate practical resistance in the field (Brent 1995) should be determined using a larger-scale plant inoculation assay.

The lower discriminatory pyrimethanil concentration of $0.5 \mathrm{mg} /$ litre used to detect sensitive isolates in this study was greater than the $0.2 \mathrm{mg} /$ litre used by Köller et al. (2005) and Henriquez et al. (2011). The isolates used in those studies came from New York and central/southern Chile respectively. Köller et al. (2005) chose a discriminatory dose to reflect a concentration slightly higher than the mean $\mathrm{ED}_{50}$ of baseline isolates. In the present experiment relatively high discriminatory concentrations were chosen to guard against false positives when screening for resistance in New Zealand orchard surveys.

The $\mathrm{EC}_{50}$ value of cyprodinil for sensitive isolates in this study was about 10 times lower than that for pyrimethanil, which appeared to reflect greater activity of cyprodinil against $V$. inaequalis. Köller et al. (2005) also found, by measuring the diameter of 7-day-old $V$. inaequalis colonies on agar, that cyprodinil had greater activity than pyrimethanil. Cyprodinil inhibited isolates from organic orchards above $0.004 \mathrm{mg} /$ litre and commercial orchard isolates above $0.024 \mathrm{mg} /$ litre, whereas pyrimethanil values were $0.11 \mu \mathrm{g} / \mathrm{ml}$ and $0.64 \mu \mathrm{g} / \mathrm{ml}$, respectively. However, the results of the present plant inoculation assay showed inconsistent differences in the in vivo activity of pyrimethanil and cyprodinil. For only one out of three resistant isolates tested was disease suppression by cyprodinil significantly greater than by pyrimethanil.

The synthetic agar method classified all seven of the isolates collected from organic orchards, where no AP fungicides had been used, as sensitive to both cyprodinil and pyrimethanil, and 10 out of 12 isolates from IFP orchards with frequent fungicide use, as resistant. This broad agreement of resistance patterns in relation to usage history of fungicides in the field gives confidence that the synthetic agar mycelial growth assay will provide a reliable method for detecting AP resistance in routine screening of $V$. inaequalis populations in New Zealand.

\section{ACKNOWLEDGEMENTS}

We wish to thank Bayer Crop Science and Syngenta Crop Protection for supplying fungicides, Peter Johnston and Paula Wilkie of Landcare Research for suggesting use of the synthetic agar, Michelle Vergara and Shamini Pushparajah for helping with mycelial growth measurements and Dr Mike Butcher of Pipfruit New Zealand Inc., Reiny Scheper and Monika Walter for reviewing a draft of this paper.

\section{REFERENCES}

Anonymous 1998. Anilinopyrimidines. In: Fungicide Resistance Action Committee (FRAC) Fungicide Use Guidelines (Principles for Effective Resistance Management), July 1998. Global Crop Protection Federation, Brussels, Belgium. 7 p.

Beresford R, Pak H, Manktelow D, Follas G, Hagerty G 1999. Strategies to avoid resistance development to anilopyrimidine fungicides in New Zealand. Proceedings of the $52^{\text {nd }} \mathrm{New}$ Zealand Plant Protection Conference: 176178. 
Beresford RM, Wright PJ, Wood PN, Park NM 2012. Sensitivity of Venturia inaequalis to myclobutanil, penconazole and dodine in relation to fungicide use in Hawke's Bay apple orchards. New Zealand Plant Protection 65: 106-113.

Beresford RM, Wright PJ, Wood PN, Park NM, Larsen NJ, Fisher BM 2013. Resistance of Venturia inaequalis to demethylation inhibitor and dodine fungicides in four New Zealand apple-growing regions. New Zealand Plant Protection 66: 274-283.

Brent KJ 1995. Fungicide resistance in crop pathogens: How can it be managed? FRAC monograph No. 1. GIFAP, Brussells, Belgium. $48 \mathrm{p}$.

Henriquez JLS, Sarmiento OV, Alarcon PC 2011. Sensitivity of Venturia inaequalis Chilean isolates to difenoconazole, fenarimol, mancozeb, and pyrimethanil. Chilean Journal of Agricultural Research 71(1): 39-44.

Köller W, Wilcox WF, Parker DM 2005. Sensitivity of Venturia inaequalis populations to anilinopyrimidine fungicides and their contribution to scab management in New York. Plant Disease 89: 357-365.

Kunz S, Lutz B, Deising H, Mendgen K 1998. Assessment of sensitivities to anilinopyrimidineand strobilurin-fungicides in populations of the apple scab fungus Venturia inaequalis. Journal of Phytopathology 146: 231-238.

Lamberth C 2012. Methionine biosynthesisinhibiting anilinopyrimidine compounds. Chapter 12.In:Lambeth C, Dinges J ed. Bioactive heterocyclic compound classes: Agrochemicals. John Wiley \& Sons Science. 302 p.
Leroux P, Chapeland F, Desbrosses D, Gredt M 1999. Patterns of cross-resistance to fungicides in Botryotinia fuckeliana (Botrytis cinerea) isolates from French vineyards. Crop Protection 18: 687-697.

Masner P, Muster P, Schmid J 1994. Possible methionine biosynthesis inhibition by pyrimidinamine fungicides. Pesticide Science 42: 163-166.

Milling JR, Richardson CJ, Daniels A 1993. Pyrimethanil inhibits hydrolytic enzyme secretion by Botrytis spp. and prevents lysis of host cells. 6th International Congress of Plant Pathology, Montreal, Canada. Abstract 3.7.15.

Milling RJ, Richardson CJ 1995. Mode of action of the aniline-pyrimidine fungicide pyrimethanil. 2. Effects on enzyme secretion in Botrytis cinerea. Pesticide Science 45: 43-48.

Miura J, Kamakura T, Maeno S, Hayashi S, Yamagushi J 1994. Inhibition of enzyme secretion in plant pathogens by mepanipyrim, a novel fungicide. Pesticide Biochemistry and Physiology 48: 222-228.

Viljanen-Rollinson SLH, Thompson S, Keenan S, Bulman S, Wright PJ, Wood PN, Park NM, Beresford RM 2013. Sensitivity to QoI fungicides in New Zealand isolates of Venturia inaequalis. New Zealand Plant Protection 66: 284-292. 